\title{
Malnutrition in pregnancy following bariatric surgery: three clinical cases of fetal neural defects
}

\author{
Gloria Pelizzo ${ }^{1 *}$, Valeria Calcaterra ${ }^{2}$, Mario Fusillo ${ }^{1}$, Ghassan Nakib ${ }^{1}$, Antonio Maria lerullo ${ }^{3}$, Alessandro Alfei ${ }^{3}$, \\ Arsenio Spinillo ${ }^{3}$, Mauro Stronati ${ }^{4}$ and Hellas Cena ${ }^{5}$
}

\begin{abstract}
Objective: Bariatric surgery results in decreased food intake and a variable degree of malabsorption. Without adequate supplementation, the most common complications of this surgery are nutritional disorders. Pregnancy following surgery for obesity is a particular condition requiring strict monitoring of nutrient intake necessary for fetal development and a favourable neonatal prognosis.

Patients: Malnutrition in pregnancy and congenital neural malformations are reported in three women who had previously undergone bariatric surgery (1,5 and 18 years before pregnancy, respectively). Two patients underwent the Roux en $Y$ bypass and one bilio-pancreatic diversion with gastroplasty. None of the three received pre-conceptional nutritional counselling. Patients 1 and 2 did not undergo postoperative nutritional surveillance; nutrient supplementation was started at 22 and 20 weeks gestation, respectively. In patient 3, supplementation was stopped at six weeks gestation.

Results: Newborns 1 and 2 presented with dorsal myelomeningocele and ventricular dilation. Both underwent surgery and a ventriculo-peritoneal shunt was inserted in the first month of life. Newborn 3 had microcephaly, bilateral microphthalmia and sensorineural deafness.

Conclusions: Diet and nutritional status, before and during pregnancy, play an important role in the early processes of fetal development and neonatal outcome. Women of childbearing age who have had bariatric surgery, should be encouraged to follow a well-balanced diet as part of a weight management strategy. They should be advised to take recommended maternal supplements.
\end{abstract}

Keywords: Maternal malnutrition, Obesity, Bariatric surgery, Neural, Malformations

\section{Background}

Obesity has reached epidemic proportions worldwide [1]. About 25\% of women meet obesity criteria and one third are of reproductive age [2]. Obesity in pregnancy represents a serious problem, because of the adverse effects on maternal and neonatal outcomes [3]. Bariatric surgery represents an alternative option for morbid obesity in those patients who have not achieved adequate weight loss with lifestyle and medical management, and/or those who suffer from complications of obesity. Surgery to treat obesity should really be reserved for those who will adhere to the lifestyle changes that are necessary for a successful

\footnotetext{
* Correspondence: g.pelizzo@smatteo.pv.it

'Department of Maternal and Children's Health, Pediatric Surgery Unit, Fondazione IRCCS Policlinico San Matteo and University of Pavia, P.le Golgi 2, Pavia 27100, Italy

Full list of author information is available at the end of the article
}

outcome All patients should meet the appropriateness criteria for bariatric surgery [3-8].

There are three main types of bariatric surgical procedures: restrictive, combined (restrictive and malabsorptive) and primarily malabsorptive. The Roux-en-Y gastric bypass and biliopancreatic diversion more effectively maintain durable weight loss.

Pregnancies following bariatric surgery are generally considered safe. Weight reduction after surgical treatment results in a significantly lower incidence of severe obesityrelated complications such as hypertension, gestational diabetes, large-for-gestational age infants and caesarean section. Nevertheless, increased incidences of miscarriage, prematurity and growth restriction have been reported in these patients $[3,4]$.

Malabsorption following bariatric surgical procedures and malnutrition may contribute to the risk for birth 
defects [3,9-11], such as neural tube defects [12,13]. Multiple genetic and environmental factors, including maternal nutrition, regulate survival and development of the embryo in early gestation [14-16].

Maternal malnutrition in pregnancy and fetal neural deformities are reported in three patients who previously underwent bariatric surgery. The importance of an early clinical nutritional evaluation by a multidisciplinary team in women undergoing surgery for obesity is highlighted.

\section{Case presentations}

\section{Case 1}

A 40 year old female became pregnant one year following a Roux-en-Y gastric bypass (Table 1). Postoperative nutritional surveillance, pre-conceptional nutritional counselling and nutrient supplementation were not adopted.

She was referred to our Department during the second trimester of gestation after the detection of fetal neural tube defect (Table 2). Clinical and nutritional assessments were made by collecting anthropometric data, biochemical laboratory data, diet and medical history, and physical evaluation (Table 3). Nutritional supplementation with vitamins and minerals was started at 22 weeks' gestation.

The newborn underwent surgery on the first day of life for posterior myelomeningocele after MRI evaluation. A ventriculo-peritoneal shunt was positioned in the first month of life to treat ventricular dilation (Table 2).

\section{Case 2}

A 22 year old female underwent an uncomplicated laparoscopic Roux-en-Y gastric bypass for obesity five years prior to becoming pregnant (Table 1). This patient was not evaluated by a nutritionist either in the postoperative period or during the pre-conceptional phase. Nutritional supplementation was not adopted.

She was admitted to our Institution during the second trimester of pregnancy after detecting a thoraco-lumbar fetal neural tube defect on ultrasound (US) (Table 2). Anthropometric and biochemical laboratory data, diet and medical history, physical evaluation were collected to perform the clinical and nutritional assessment (Table 3).
Nutrient supplementation was immediately introduced during the $20^{\text {th }}$ week.

At birth, prenatal findings of myelomeningocele extending from T9-S1 were confirmed by MRI (Table 2). Closure of myelomeningocele was performed at the first day of life and a ventriculo-peritoneal drainage tube was positioned one month later.

\section{Case 3}

A 35 year old woman became pregnant 18 years after bariatric surgery consisting of bilio-pancreatic diversion with gastroplasty (Table 1). She was referred at the third trimester of pregnancy for fetal microcephaly. The patient reported stopping nutritional supplementation at six weeks gestation. Moreover, she refused nutritional care and supplements prescribed after bariatric surgery (BS) until she had two spontaneous abortions 16 years post BS. Nutritional data of the patient are reported in Table 3.

The newborn male at 35 weeks gestation weighing $2287 \mathrm{~g}$, presented with microcephaly, bilateral micro/anophthalmia, skeletal dysplasia, short limbs and persistent ductus arteriosus. Bilateral microphthalmia with optic nerve, chiasm and tract hypotrophy were documented by MRI. Sensorineural deafness was also diagnosed. Infectious and genetic causes of microphthalmia were excluded. He underwent positioning of a prosthetic eye and cochlear devices at 5 and 16 months, respectively. A gastrostomy feeding tube was also inserted during the first year of life to treat his failure to thrive; enteral nutrient supplementation for the infant was stopped at two years of age.

Clinical, nutritional and anthropometric data of the mothers are reported in Tables 1 and 3.

In Table 2, prenatal imaging and neonatal outcome are provided.

\section{Conclusions}

Maternal nutritional status may be involved in the etiology of fetal neural tube defects (NTDs). In this report, we describe micronutrient and/or vitamin deficiency in three pregnant women who had previously undergone bariatric surgery and gave birth to progeny with congenital neural defects.

Table 1 Clinical and anthropometric data of the three mothers

\begin{tabular}{|c|c|c|c|}
\hline & MOTHER 1 & MOTHER 2 & MOTHER 3 \\
\hline Age at bariatric surgery (years) & 39 & 22 & 17 \\
\hline Co-morbidities at surgery & no & no & no \\
\hline Bariatric procedure & roux en $Y$ gastric bypass & roux en $Y$ gastric bypass & bilio-pancreatic diversion with gastroplasty \\
\hline $\mathrm{BMI}$ at bariatric surgery $\left(\mathrm{kg} / \mathrm{m}^{2}\right)$ & 40 & 40.5 & 48 \\
\hline Pre-gravidic BMI $\left(\mathrm{kg} / \mathrm{m}^{2}\right)$ & 23.4 & 25.4 & 24.2 \\
\hline Age at pregnancy (years) & 40 & 27 & 35 \\
\hline $\begin{array}{l}\text { Time interval between bariatric } \\
\text { surgery and pregnancy (years) }\end{array}$ & 1 & 5 & 18 \\
\hline
\end{tabular}


Table 2 Fetal and neonatal outcome

\begin{tabular}{|c|c|c|c|}
\hline & CASE 1 & CASE 2 & CASE 3 \\
\hline \multicolumn{4}{|l|}{ FETAL OUTCOME } \\
\hline Gestational age at diagnosis (weeks + days) & $22+0$ & $20+5$ & $20+3$ \\
\hline \multicolumn{4}{|l|}{ Ultrasound findings } \\
\hline \multicolumn{4}{|l|}{ Indirect signs } \\
\hline Deformation of frontal cranial bones (lemon sign) & Present & Present & Absent \\
\hline Abnormal curvature of cerebellum (banana sign) & Present & Present & Absent \\
\hline Ventricle dilatation (site; grade) & Bilateral; Moderate & Bilateral; Moderate & Absent \\
\hline Hypoplastic posterior cranial fossa & Present & Present & Absent \\
\hline \multicolumn{4}{|l|}{ Direct signs } \\
\hline Spinal deformation (level of lesion) & Lumbar L1-L5 & Thoracic Lumbar (T9-S1) & Absent \\
\hline Myelomeningocele (dimension mm) & Present (27×28) & Present $(54 \times 37)$ & Absent \\
\hline Other associated malformations & Sacral Agenesia & Hemivertebrae T5 & Absent \\
\hline \multicolumn{4}{|l|}{ Magnetic resonance imaging } \\
\hline Findings & $\begin{array}{c}\text { Moderate bilateral ventriculomegaly } \\
\text { (Arnold Chiari Type II); spina bifida } \\
\text { extending from T1-T5 }\end{array}$ & $\begin{array}{l}\text { Moderate bilateral ventriculomegaly } \\
\text { (Arnold Chiari Type I); spina } \\
\text { bifida extending from T9-S1 }\end{array}$ & Not Performed \\
\hline \multicolumn{4}{|l|}{ NEONATAL OUTCOME } \\
\hline Sex & $\mathrm{F}$ & $\mathrm{F}$ & M \\
\hline Gestational age at birth (weeks; days) & 38 & 38 & $34+6$ \\
\hline Mode of delivery & Elective Caesarean Section & Elective Caesarean Section & Vaginal \\
\hline \multicolumn{4}{|l|}{ Apgar score } \\
\hline 1 minute & 6 & 8 & 5 \\
\hline 5 minutes & 7 & 9 & 7 \\
\hline Weight at birth (gr) & 2700 & 3090 & 2287 \\
\hline Surgery & Closure MMC + DVP & Closure MMC + DVP & - \\
\hline
\end{tabular}

$\mathrm{MMC}=$ myelomeningocele; DVP = drainage ventriculo-peritoneal.

Any bariatric procedure may lead to an increased risk of nutritional deficiency during the postoperative period [17]. The mechanism of malnutrition following bariatric procedures is quite complex. Risk factors may include preoperative malnutrition (e.g., vitamin D, iron), decreased food intake (dumping syndrome, reduced hunger and increased satiety, food intolerances), inadequate nutrient supplementation (poor compliance with multivitamin/multimineral regimen, insufficient amounts of vitamins and/or minerals in supplements) and/or nutritional support (lack of follow-up, insufficient monitoring, difficulty in recognizing symptoms of deficiency), nutrient malabsorption (reduced absorptive gastro-intestinal area) $[18,19]$.

All patients after bariatric surgery should take vitamins and microelements to prevent micronutrient deficiencies. Unfortunately, more than $40 \%$ of women after these surgical procedures do not take multiple vitamin supplements for long periods of time [2], with a consequent high risk for malnutritional complications, especially during pregnancy when an increased requirement for microelements and vitamins is recognized.
Women should be instructed to avoid pregnancy for 12 24 months following bariatric surgery, since this is the period of most rapid weight loss $[8,11]$. If an unplanned pregnancy occurs during this period, nutritional assessment should be carried out immediately and frequently monitored during the entire gestational period, especially when deficiencies are detected. Nutrients such as vitamins A, B6, B12 and folic acid and zinc affect embryogenesis and a deficiency in any of these elements may be related to spontaneous abortion failure and to a spectrum of neurodevelopmental disorders [16].

Brain and spinal cord development arises early in pregnancy (18-28 days) from specialised cells. The timing of their development enhances the importance of adequate maternal nutrition before gestation and in the first trimester [20-22]. In particular, folic acid, vitamin B12 and vitamin A and its biologically active metabolite retinoic acid are thought to be involved in neurulation and subsequent neural tube growth and patterning [20].

Fetal neurologic malformations result from failed neural tube closure and/or neural crest migration. 
Table 3 Maternal nutritional findings during pregnancy

\begin{tabular}{|c|c|c|c|}
\hline & MOTHER 1 & MOTHER 2 & MOTHER 3 \\
\hline Clinical signs & fatigue & fatigue & nyctalopia \\
\hline Nutritional supplements before pregnancy & no & no & yes \\
\hline Nutritional supplements during first trimester & no & no & no \\
\hline Nutritional status during pregnancy (gestational age) & $24 w$ & $20 w$ & $22 w$ \\
\hline -Folates (ng/ml; nv 2-19.9) & 5.1 & $>24$ & * \\
\hline -Vitamin B12 (pg/ml; nv 243-894) & 201 & $<15$ & * \\
\hline -Vitamin A (mcg/ml; nv 0.25-0.86) & 0.24 & 0.1 & * \\
\hline -1,25-dihydroxyVitD (pmol/L; nv 48-110) & 44.6 & 40.3 & * \\
\hline -25-hydroxyVitD (nmol/L; nv 23-113) & 40.30 & 76.28 & * \\
\hline -Iron (mcg/dl; nv 25-156) & 16 & 73 & * \\
\hline -Ferritin (ng/ml; nv 18-440) & 2 & 10 & $*$ \\
\hline$-\mathrm{Hb}(\mathrm{g} / \mathrm{dl} ; \mathrm{nv} 11.7-15.5)$ & 8.7 & 12 & * \\
\hline -Pre-albumin levels (mg/dl; nv 20-40) & 19 & 17 & - \\
\hline
\end{tabular}

$\mathrm{nv}=$ normal value range.

*hypovitaminosis as reported by the patient. Clinical records not available.

Neural tube defects (NTDs) are common congenital malformations of the central nervous system. NTDs resulting from failed complete neural tube closure at the rostral or caudal end lead to anencephaly and spina bifida [21]. In cases 1 and 2, dorsal myelomeningocele resulted from a defect in primary neurulation including exposition of neural tissue and cerebrospinal fluid leakage. The total prevalence of NTD-affected pregnancies ranges between 0.4 and 2 per 1000 in European countries. The NTD process involves multiple genes, nutritional and environmental factors [23], and seems to be related to defects in the folate-methionine metabolic pathway, since vitamin B12 and folic acid preconception supplementation has been proven to substantially reduce the risk of having an NTD affected pregnancy [15,22-24].

Neural crest cell migration defects contribute to malformation of the optic and acoustic pathways. Signs of congenital ocular abnormalities such as microphthalmia, characterized by abnormally small eyes with or without structural abnormalities, may depend on vitamin A deficiency leading to a disruption of ocular development [20,25]. Anophthalmia/microphthalmia have their genesis in early gestation and are the result of failure of the anterior neural tube or optic pits to enlarge and form optic vesicles or degeneration and disappearance of the optic vesicle [26]. When optic nerve, chiasm and/or tracts with micro/anophthalmia are observed this may indicate the regression of a partially developed eye rather than aplasia of the optic vesicle. The prevalence of anophthalmia and microphthalmia has been estimated to be 3 and 14 per 100,000 births, respectively [27].

The precise pathogenesis of these conditions remains unknown, but non-genetic and non-infectious causes have been postulated and include maternal vitamin $\mathrm{A}$ deficiency [25]. It has been demonstrated that in animal models, deprivation of retinoic acid (RA) during eye development causes microphthalmia as well as other visual defects [20] and the timing of the RA deficiency is critical to developmental outcome [28]. Glichrist $\mathrm{H}$ et al. [29] and Smets et al. [30] described two cases of microphthalmia and ocular malformations in infants whose mothers had undergone biliopancreatic diversion surgery for obesity with documented hypovitaminosis A.

The clinical evidence of nyctalopia in our third case is thought to be related to hypovitaminosis A, as reported by the patient. The baby also exhibited complex congenital malformations including microphthalmia and optic nerve, chiasm and tract hypoplasia; this condition might be correlated to abnormal neural crest cell migration or to degeneration of the optic vesicle induced by vitamin deficiency [25].

A multidisciplinary health care approach in this setting should include surgeons, nutritionists, obstetricians, endocrinologists, cardiologists and primary care physicians. Nutritional counseling, for assessment and supplementation, should be performed before and following bariatric surgery to reduce the related risks of fetal malformations.

Protein, iron, folate, calcium, vitamin $\mathrm{B}_{12}$ and $\mathrm{D}$ are the most common nutrient deficiencies following procedures that induce malabsorption [17]. Pre and postconception micro-nutrient status assessment is strongly recommended in women who have undergone bariatric surgery. Nutritional therapy should be initiated right away upon any nutrient deficit detection. When no deficits are detected, a complete blood count and measurement of iron, ferritin, folic acid, vitamin B12, vitamin A, 25-hydroxyvitamin D, calcium, and parathyroid hormone levels should be performed every trimester. 
Nutrient deficiencies may also occur after restrictive surgical procedures, such as adjustable gastric banding, because of decreased food intake and dietary imbalances. There is no consensus on the management of pregnant women who undergo this procedure, but early consultation with a clinical nutritionist is recommended.

Lifelong nutritional education and lifestyle changes in women of childbearing age following bariatric surgery are essential for a successful pregnancy outcome. The main goals of medical nutrition therapy during pregnancy are to ensure acceptable weight gain, promote fetal growth and development and provide adequate vitamin, mineral and protein intake. Former recipients of bariatric surgery are recommended to continue supplements before and during pregnancy. Educational support and assessments to verify nutritional requirements are also strongly recommended.

\section{Consent}

Written informed consent was obtained from the patients for the publication of this case report.

Abbreviations

BS: Bariatric surgery; NTDs: Neural tube defects; RA: Retinoid acid.

\section{Competing interests}

The authors declare that they have no competing interests.

\section{Authors' contributions}

GP: provided surgical support and contributed to the writing of the final manuscript. VC: provided pediatric support and contributed to the writing of the manuscript draft. MF: provided surgical support. GN: provided surgical support and contributed to the writing of the manuscript draft. AMl: provided gynecological support and contributed to the writing of the manuscript draft. AA and AS: provided gynecological support. MS: provided neonatal support. HC: provided nutritional support and contributed to the writing of the manuscript draft. All authors read and approved the final manuscript.

\section{Acknowledgements}

GP thanks the Fondazione IRCCS Policlinico S. Matteo for support of the project "Prenatal therapy for prenatal maldevelopment".

\section{Author details \\ 'Department of Maternal and Children's Health, Pediatric Surgery Unit, Fondazione IRCCS Policlinico San Matteo and University of Pavia, P.le Golgi 2, Pavia 27100, Italy. ${ }^{2}$ Department of Internal Medicine, University of Pavia and Department of Maternal and Children's Health, Pediatric Unit, Fondazione IRCCS Policlinico San Matteo Pavia, P.le Golgi 2, Pavia 27100, Italy. ${ }^{3}$ Department of Maternal and Children's Health, Obstetrics and Gynecology Unit, Fondazione IRCCS Policlinico San Matteo Pavia and University of Pavia, P.le Golgi 2, Pavia 27100, Italy. ${ }^{4}$ Department of Maternal and Children's Health, Neonatal Intensive Care Unit, Fondazione IRCCS Policlinico San Matteo Pavia, P.le Golgi 2, Pavia 27100, Italy. ${ }^{5}$ Department of Public Health, Neurosciences, Experimental and Forensic Medicine, Section of Human Nutrition, University of Pavia, Cascina Cravino, Pavia 27100, Italy.}

Received: 13 December 2013 Accepted: 6 June 2014 Published: 14 June 2014

\section{References}

1. World Health Organization: Obesity and overweight; [www document] URL http://www.who.int/dietphysicalactivity/publications/wha/en/ [accessed on 17 Dec 2008]

2. Kaska L, Kobiela J, Abacjew-Chmylko A, Chmylko L, Wojanowska-Pindel M, Kobiela P, Walerzak A, Makarewicz W, Proczko-Markuszewska M, Stefaniak T:
Nutrition and Pregnancy after Bariatric Surgery. ISRN Obes 2013, 2013:492060.

3. Eerdekens A, Debeer A, Van Hoey G, De Borger C, Sachar V, Guelinckx I, Devlieger R, Hanssens M, Vanhole C: Maternal bariatric surgery: adverse outcomes in neonates. Eur J Pediatr 2010, 169:191-196.

4. Maggard MA, Yermilov I, Li Z, Maglione M, Newberry S, Suttorp M, Hilton L, Santry HP, Morton JM, Livingston EH, Shekelle PG: Pregnancy and fertility following bariatric surgery: a systematic review. JAMA 2008, 300:2286-2296.

5. National Institutes of Health: Gastrointestinal surgery for severe obesity: National Institutes of Health consensus development conference statement. Am J Clin Nutr 1992, 55(2):615S-619S.

6. National Institutes of Health: Gastrointestinal surgery for severe obesity. Consensus Development Conference Panel. Ann Intern Med 1991, 115:956-961.

7. National Institutes of Health: Clinical guidelines on the identification, evaluation, and treatment of overweight and obesity in adults. The evidence report. Obes Res 1998, 6(2):51S-209S.

8. Yermilov I, McGory ML, Shekelle PW, Ko CY, Maggard MA: Appropriateness criteria for bariatric surgery: beyond the NIH guidelines. Obesity 2009, 17:1521-1527.

9. Alatishe A, Ammori BJ, New JP, Syed AA: Bariatric surgery in women of childbearing age. QJM 2013, 106:717-720.

10. Flum DR, Salem L, Elrod JA, Dellinger EP, Cheadle A, Chan L: Early mortality among Medicare beneficiaries undergoing bariatric surgical procedures. JAMA 2005, 294:1903-1908.

11. Mechanick Jl, Youdim A, Jones DB, Timothy Garvey W, Hurley DL, Molly McMahon M, Heinberg LJ, Kushner R, Adams TD, Shikora S, Dixon JB, Brethauer S: Clinical practice guidelines for the perioperative nutritional, metabolic, and nonsurgical support of the bariatric surgery patient 2013 update: cosponsored by American association of clinical endocrinologists, the obesity society, and american society for metabolic and bariatric surgery. Surg Obes Relat Dis 2013, 9:159-191.

12. Martin L, Chavez GF, Adams MJ Jr, Mason EE, Hanson JW, Haddow JE, Currier RW: Gastric bypass surgery as maternal risk factor for neural tube defects. Lancet 1988, 1:640-641.

13. Moliterno JA, DiLuna ML, Sood S, Roberts KE, Duncan CC: Gastric bypass: a risk factor for neural tube defects? Case report. J Neurosurg Pediatr 2008, 1:406-409.

14. Hovdenak N, Haram K: Influence of mineral and vitamin supplements on pregnancy outcome. Eur J Obstet Gynecol Reprod Biol 2012, 164:127-132.

15. Pepper MR, Black MM: B12 in fetal development. Semin Cell Dev Biol 2011, 22:619-623.

16. Ramakrishnan U, Grant F, Goldenberg T, Zongrone A, Martorell R: Effect of women's nutrition before and during early pregnancy on maternal and infant outcomes: a systematic review. Paediatr Perinat Epidemiol 2012, 26:285-301.

17. Bal BS, Finelli FC, Shope TR, Koch TR: Nutritional deficiencies after bariatric surgery. Nat Rev Endocrinol 2012, 8:544-556.

18. Xanthakos SA: Nutritional deficiencies in obesity and after bariatric surgery. Pediatr Clin North Am 2009, 56:1105-1121.

19. Gletsu-Miller N, Wright BN: Mineral malnutrition following bariatric surgery. Adv Nutr 2013, 4:506-517.

20. Le HG, Dowling JE, Cameron DJ: Early retinoic acid deprivation in developing zebrafish results in microphthalmia. Vis Neurosci 2012, 29:219-228.

21. Copp AJ, Brook FA, Estibeiro JP, Shum ASW, Cockcroft DL: The embryonic development of mammalian neural tube defects. Prog Neurobio/ 1990, 35:363-403.

22. Safi J, Joyeux L, Chalouhi GE: Periconceptional folate deficiency and implications in neural tube defects. J Pregnancy 2012, 2012:295083.

23. Agopian AJ, Tinker SC, Lupo PJ, Canfield MA, Mitchell LE, National Birth Defects Prevention Study: Proportion of neural tube defects attributable to known risk factors. Birth Defects Res A Clin Mol Teratol 2013, 97:42-46.

24. Spencer PS, Palmer VS: Interrelationships of undernutrition and neurotoxicity: food for thought and research attention. Neurotoxicology 2012, 33:605-616.

25. Verma AS, Fitzpatrick DR: Anophthalmia and microphthalmia. Orphanet J Rare Dis 2007, 2:47

26. Fuhrmann S: Eye morphogenesis and patterning of the optic vesicle. Curr Top Dev Biol 2010, 93:61-84.

27. Morrison D, FitzPatrick D, Hanson I, Williamson K, Van Heyningen V, Fleck B, Jones I, Chalmers J, Campbell H: National study of microphthalmia, 
anophthalmia, and coloboma (MAC) in Scotland: investigation of genetic aetiology. J Med Genet 2002, 39:16-22.

28. Forsum E, Brantsæter AL, Olafsdottir AS, Olsen SF, Thorsdottir I: Weight loss before conception: A systematic literature review. Food Nutr Res 2013, 57: doi:10.3402/fnr.v57i0.20522. Epub 2013 Mar 13.

29. Gilchrist H, Taranath DA, Gole GA: Ocular malformation in a newborn secondary to maternal hypovitaminosis A. J AAPOS 2010, 14:274-276.

30. Smets K, Barlow T, Vanhaesebrouck P: Maternal vitamin A deficiency and neonatal microphthalmia: complications of biliopancreatic diversion? Eur J Pediatr 2006, 165:502-504.

doi:10.1186/1475-2891-13-59

Cite this article as: Pelizzo et al: Malnutrition in pregnancy following bariatric surgery: three clinical cases of fetal neural defects. Nutrition Journal 2014 13:59.

\section{Submit your next manuscript to BioMed Central and take full advantage of:}

- Convenient online submission

- Thorough peer review

- No space constraints or color figure charges

- Immediate publication on acceptance

- Inclusion in PubMed, CAS, Scopus and Google Scholar

- Research which is freely available for redistribution 